\title{
Genetics of suicide attempts in individuals with and without mental disorders: a population-based genome-wide association study
}

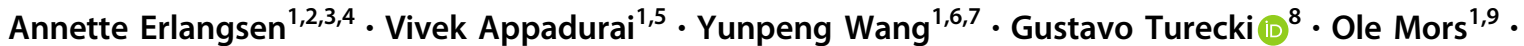 \\ Thomas Werge ${ }^{1,5,10}$ - Preben B. Mortensen $\circledast^{1,11}$ - Anna Starnawska ${ }^{1,12} \cdot$ Anders D. Børglum ${ }^{1,12,13}$. \\ Andrew Schork ${ }^{1,5} \cdot$ Ron Nudel $\mathbb{1}^{1,5} \cdot$ Marie Bækvad-Hansen ${ }^{1,14}$ - Jonas Bybjerg-Grauholm (1) ${ }^{1,14}$. \\ David M. Hougaard $\mathbb{D}^{1,14} \cdot$ Wesley K. Thompson ${ }^{1,6,7,9,15} \cdot$ Merete Nordentoft ${ }^{1,2,10,16} \cdot$ Esben Agerbo $\mathbb{C}^{1,11}$
}

Received: 13 February 2018 / Revised: 14 May 2018 / Accepted: 4 June 2018 / Published online: 16 August 2018

(c) Springer Nature Limited 2018

\begin{abstract}
Family studies have shown an aggregation of suicidal behavior in families. Yet, molecular studies are needed to identify loci accounting for genetic heritability. We conducted a genome-wide association study and estimated single nucleotide polymorphisms (SNP) heritability for a suicide attempt. In a case-cohort study, national data on all individuals born in Denmark after 1981 and diagnosed with severe mental disorders prior to $2013(n=57,377)$ and individuals from the general population $(n=30,000)$ were obtained. After quality control, the sample consisted of 6024 cases with an incidence of suicide attempt and 44,240 controls with no record of a suicide attempt. Suggestive associations between SNPs, rs6880062 ( $p$-value: $\left.5.4 \times 10^{-8}\right)$ and rs6880461 $\left(p\right.$-value: $\left.9.5 \times 10^{-8}\right)$, and suicide attempt were identified when adjusting for sociodemographics. Adjusting for mental disorders, three significant associations, all on chromosome 20, were identified: rs4809706 ( $p$-value: $2.8 \times 10^{-8}$ ), rs4810824 ( $p$-value: $3.5 \times 10^{-8}$ ), and rs6019297 ( $p$-value: $4.7 \times 10^{8}$ ). Sub-group analysis of cases with affective disorders revealed SNPs associated with suicide attempts when compared to the general population for gene PDE4B. All SNPs explained 4.6\% [CI-95: 2.9-6.3\%] of the variation in suicide attempt. Controlling for mental disorders reduced the heritability to $1.9 \%$ [CI-95: 0.3-3.5\%]. Affective and autism spectrum disorders exhibited a SNP heritability of 5.6\% [CI-95: 1.9-9.3\%] and 9.6\% [CI-95: 1.1-18.1\%], respectively. Using the largest sample to date, we identified significant SNP associations with suicide attempts and support for a genetic transmission of suicide attempt, which might not solely be explained by mental disorders.
\end{abstract}

\section{Introduction}

The lifetime prevalence of suicide attempts is estimated to be $2.7 \%[1,2]$. Family studies using clinical and epidemiological data have consistently shown an aggregation of suicidal behavior in families [3-7]. Both twin and adoption studies have indicated that genes account for as

Shared first authorship: Annette Erlangsen, Vivek Appadurai.

Shared last authorship: Merete Nordentoft, Esben Agerbo.

Electronic supplementary material The online version of this article (https://doi.org/10.1038/s41380-018-0218-y) contains supplementary material, which is available to authorized users.

Annette Erlangsen

Annette.Erlangsen@ regionh.dk

Extended author information available on the last page of the article much as $30-50 \%$ of the observed familial aggregation [810]. Hence, molecular studies have attempted to identify specific genes that contribute to suicide risk [11].

The advantage of molecular genetic studies lies in the estimation of genetics effects via single nucleotide polymorphisms (SNPs) rather than through familial relationships. Candidate gene and genome-wide association study (GWAS) designs have identified numerous loci associated with suicide attempts, including 5HTR2A (rs1885884) [12]; a locus on $2 \mathrm{p} 25$ (rs300774) [11, 13]; and $A B I 3 B P$ (rs2576377) [14] among others [15]. Still, to date most molecular genetic studies, even combined ones, have been conducted on small sample sizes (sample $<8900$; cases <2810) [11, 16], implying that they potentially were underpowered and subject to false positives as well as false negatives. Additionally, studies have rarely adjusted for mental disorders or included a non-psychiatric, population-representative sample. 
Mental disorders are strongly linked to suicidal behavior [17-19]. Indeed, often mental disorders and suicidality are seen as clinically related, e.g., suicidal ideation is considered as a qualifying symptom for the diagnosis of depression. Given that liability for a wide range of mental disorders is associated with a common set of genetic factors $[20,21]$, it is plausible that the effect of genes on suicidal behavior could be mediated through their impact on mental disorders $[11,22,23]$. Although family studies have indicated support for a generic transmission of suicidal behavior independent of mental disorders $[3,4,6,10,22,23]$, this remains to be confirmed using molecular genetic data.

The aim of this study was to examine whether specific genetic variants are associated with suicide attempt in a population-based sample of individuals with and without severe mental disorders using a GWAS approach while controlling for mental disorders. In addition, we aimed to estimate the heritability explained by common genetic variation while taking mental disorders into account.

\section{Material and methods}

\section{Design and data source}

We used a nested case-cohort study design [24]. In Denmark, a unique personal id-number is assigned to all persons born or migrating into the country [25]. This id-number was introduced in 1968 and is listed in the Danish Civil Registration System along with data on gender, birth date, and parents' id number [26]. Since 1981, blood samples from all newborns in Denmark have been archived in the Danish Newborn Screening Biobank at the Danish Statens Serum Institut [27, 28]. Likewise, individual records of all hospital contacts for mental and somatic disorders have been recorded in the Danish Psychiatric Central Research Register since 1968 and the National Registry of Patients since 1977, respectively [29, 30].

\section{Sample}

The iPSYCH dataset was constructed from complete and consecutive birth cohorts of all singletons born in Denmark between May 1, 1981 and December 31, 2005 [31]. Among individuals who were residents on their first birthday ( $N=1,472,762$ persons), those who later were diagnosed with one or more severe mental disorders prior to $31 \mathrm{st}$ December $2012(n=57,377)$ were selected. Severe mental disorders were identified as the following diagnoses recorded according to the 10th revision of International Classification of Diseases (ICD-10) [32]: schizophrenia (F20), bipolar disorders (F30, F31), affective disorders (F30-39), autism spectrum disorders (F84.0, F84.1, F84.5, F84.8, or
F84.9), anorexia (F50), and ADHD (F90.0). In addition, a population-based random sample of individuals $(n=30,000)$ was included in iPSYCH [31].

\section{Cases}

Individuals in the iPSYCH sample who at some point prior to December 31, 2012 had been recorded with one or more incidents of non-fatal suicide attempts were considered as cases. Suicide attempts were identified by screening the Danish Psychiatric Central Research Register and the National Registry of Patients for diagnoses of suicide attempts (ICD-10: X60-X84). In addition, contacts where the "reasons for contact"-variable indicated suicide attempt were included, as well as combinations of diagnoses where the main diagnosis had been recorded as a mental disorder (ICD-10: $\mathrm{F}$ chapter) together with a diagnosis of poisoning by drugs or other substances (ICD-10: T36-T50, T52-T60) or injuries to hand, wrist, and forearm (ICD-10: S51, S55, S59, S61, S65, S69). This is a well-established proxy for suicide attempt $[33,34]$.

\section{Controls}

All persons who had not been recorded with one or more suicide attempts were included in the control group. The control group consisted of persons with mental disorders as well as persons with no mental disorders.

\section{Extraction and genotyping}

The Danish Newborn Screening Biobank consists of blood spot samples from almost 100\% of all newborns in Denmark, which are collected 4-7 days after birth through heel prick and stored at $-20{ }^{\circ} \mathrm{C}[27,28,35]$. Two $3.2 \mathrm{~mm}$ disks were punched from blood spots for each individual. Genomic DNA was extracted and whole genome amplified (WGA) with the use of Extract-N-Amp Blood PCR Kit (Sigma-Aldrich, Seelze, Germany) and RepliG kit (Qiagen, Venlo, The Netherlands) [35, 36]. Genotyping was carried out using Infinium PsychChip v1.0 array (Illumina, San Diego, CA, USA) according to the manufacturer's instructions and handled by the Broad Institute (Boston, MA, USA) over 23 waves. The extraction and genotyping procedures have previously been tested by comparing call and conflict rates of WGA DNA from $>20$-year-old stored blood spots with those of high quality, recent genomic DNA from the same individuals; concluding a high quality of the WGA DNA [35, 37].

\section{Genotype quality control and imputation}

After initial genotyping and quality control at the Broad Institute, a total of 77,639 subjects and 554,360 SNPs were 
obtained. A subset of 246,369 high-quality SNPs was identified by excluding SNPs showing deviations from the Hardy-Weinberg equilibrium ( $p$-value $<1 \times 10^{-6}$ ) in controls, minor allele frequencies $<1 \%$, multi-allelic SNPs, and SNPs in non-autosomal loci within a subset of individuals with a homogenous European ancestry. This set of highquality SNPs were pre-phased using SHAPEIT3 [38] and the resulting haplotypes were imputed in 10 batches using IMPUTE2 [39] and the 1000 genomes phase 3 reference haplotypes, which yielded a total of 80.7 million variants.

The post-imputation quality control excluded SNPs for the following, non-exclusive reasons: variants with minor allele frequencies $<0.001 \quad(n \approx 67$ million $)$; variants with imputation INFO scores $<0.2(n \approx 17$ million); SNPs missing in more than $10 \%$ of the imputed samples $(n \approx 1.8$ million); SNPs showing strong associations to genotyping wave $(n \approx 291,937)$ or imputation batch $\left(p<5 \times 10^{-8}\right)(n=$ 33); SNPs showing differential imputation quality between psychiatric cases and controls $\left(p<1 \times 10^{-6}\right)(n \approx 527,912)$; and SNPs violating Hardy-Weinberg equilibrium in controls. Finally, a total of 11,601,089 markers were retained.

\section{Population stratification and kinship}

Principal components of genetic ancestry were generated using Eigensoft smartPCA [40]. Using a subset of 47,856 individuals whose parents and grandparents were born in Denmark as our reference, we censored individuals deviating from the multivariate mean of the joint distribution of first 10 principal components. Principal components were re-generated using the remaining samples and the second round of censoring was performed. KING was used to generate kinship coefficients to ensure that no two samples were related beyond the second degree [41]. The imputation and quality control process has previously been documented [42].

\section{Statistical analysis}

The GWAS was conducted by comparing the imputed additive genotype dosages between cases with one or more suicide attempts to controls with no recorded suicide attempt. Logistic regressions were applied to calculate log odds ratios and 95\% confidence intervals using PLINK2 [43] and the R package qqman [44] to generate Manhattan plots. The level of significance and suggestive significance was set to $p<5 \times 10^{-8}$ and $p<5 \times 10^{-6}$, respectively. Two different GWAS models were employed; Model 1 contained covariates on gender, years under follow-up where the participant was 15 years of age or older, and the first 10 principal components of genetic ancestry. Model 2: In addition to the covariates used in Model 1, binary covariates for diagnosis of schizophrenia, bipolar disorders, affective disorders, autism spectrum disorders, anorexia, and any other disorder (ICD-10: F chapter) were included. In a third association study, we compared 4302 individuals with affective disorder and at least one recorded suicide attempt to 14,938 controls with affective disorders and no suicide attempt. However, a lack of association was attributed to low statistical power and the model was modified by using only population-based sample of healthy controls $(n=$ $13,294)$ while adjusting for socio-demographic conditions.

The GREML approach implemented in the genome-wide complex trait analysis (GCTA) software package was utilized to estimate the SNP variation [45]. A genetic relatedness cutoff of 0.034 was applied to account for cryptic relatedness between samples. The analysis was adjusted for the same covariates as Model 1.

\section{Enhancer annotations}

Enhancer annotations were taken from the GeneHancer database [46], and enhancer IDs corresponded to those in GeneCards (v4.6.0 Build 15). SNP positions were converted to genome build hg38 using the UCSC liftOver [47] and were subsequently mapped onto enhancers using BEDTools [48].

\section{Ethical permission}

Anonymized data were stored in the Computerome database at the Technical University of Denmark with restricted access. The project has been approved by the Danish Scientific Ethics Committee, the Danish Health Data Authority, the Danish Data Protection Agency, and Danish Newborn Screening Biobank Steering Committee.

\section{Results}

In all, 77,639 individuals born in Denmark between May 1, 1981 and December 31, 2005 were genotyped. Of these, 12,128 participants were excluded during the quality control and 15,247 did not reach the age of 15 during follow-up (Supplementary Figure 1).

The sample consisted of 50,264 individuals over the age of 15 years on December 31, 2012. Of these, 6024 (12.0\%) persons had been recorded with a suicide attempt while the remaining 44,240 (88.0\%) were considered as controls (Supplementary Table 1).

The results of the GWAS for Model 1 (genomic inflation factor, $\lambda_{\mathrm{gc}}=1.04$ ) showed suggestive associations on chromosomes 1, 19, and 20. Furthermore, associations for SNPs rs6880062 (NC_000005.9:g.153298025A $>$ G; $p$-value: $5.4 \times 10^{-8}$ ) and rs6880461 (NC_000005.9: g. $153298024 \mathrm{G}>\mathrm{A}$; $p$-value: $9.5 \times 10^{-8}$ ) on chromosome 5 


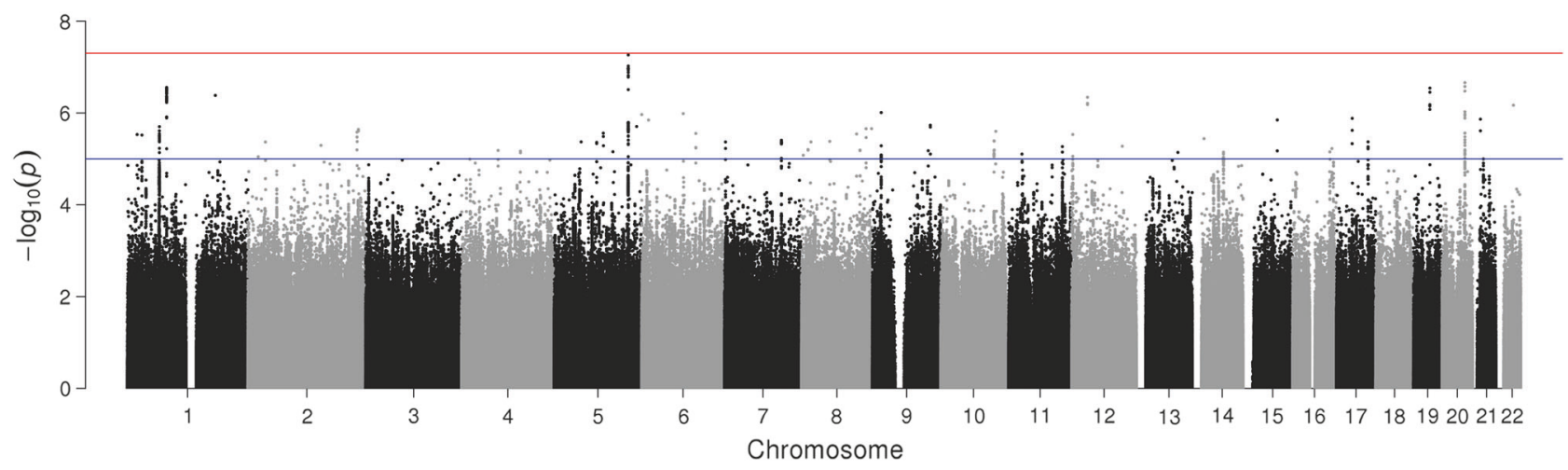

Fig. 1 Manhattan plot of genome-wide association study (GWAS) of suicide attempt adjusted for: gender, number of years under follow-up being (aged $\geq 15$ years), first 10 principal components of genetic ancestry (Model 1). Note: The red line marks the threshold of $p=5 \times$ $10^{-8}$ for significant associations while the blue line marks the threshold of $p=5 \times 10^{-6}$ for suggestive associations fell short of genome-wide significance, as seen in Fig. 1 and Table 1.

GWAS Model 2 (genomic inflation factor, $\lambda_{\mathrm{gc}}=1.02$ ), revealed three genome-wide significant SNPs; rs4809706 (NC_000020.10:g.47193719A>G; $p$-value: $2.8 \times 10^{-8}$ ), rs4810824 (NC_000020.10:47193708G>C; $p$-value: $3.5 \times$ $10^{-8}$ ), and rs6019297 (NC_000020.10:g.47197230C >T; $p$ value: $4.7 \times 10^{-8}$ ) on chromosome 20 (Fig. 2). In addition, suggestive associations were noted on chromosomes 6,8 , and 9. The three significant SNPs showed suggestive associations in Model 1.

The third association study comparing individuals with depressive disorder and a suicide attempt to healthy controls (genomic inflation factor $\lambda_{\mathrm{gc}}=1.08$ ) revealed a genomewide significant locus on chromosome 1 with the lead SNP rs4554696 (NC_000001.10:g.66408011C $>$ T; $p$-value: $5.63 \times 10^{-9}$ OR $\left.=0.85 \pm 0.0595 \% \mathrm{CI}\right)$ and suggestive associations on chromosomes 2, 5, and 9 (Fig. 3). The Manhattan plot for the GWAS and a GTEX expression plot [49] for PDE4B are presented in Supplementary Figure 2-3 and Supplementary Table 2.

The SNP heritability of suicide attempt was found to be 4.6\% [CI-95: 2.9-6.3\%] when adjusting for sociodemographic characteristics (Table 2). When introducing diagnosed mental disorders as binary covariates in the GCTA model, SNP heritability was reduced to $1.9 \%$ [CI95: $0.3-3.5 \%$ ]. Calculation of SNP heritability among people with no mental disorders did not render a significant estimate $[\mathrm{OR}=3.3 \%$; CI-95: -0.1 to $7.6 \%$ ], while a significant $h^{2}$ estimate of $2.8 \%$ [0.7-4.9\%] was noted within subjects with mental disorders. The SNP heritability was further estimated within each subgroup of mental disorders while adjusting for socio-demographic covariates. Individuals with affective disorders were estimated to carry a significant SNP heritability of 5.6\% [1.9-9.3\%] while those with autism spectrum disorders had 9.6\% [1.1-18.1\%]. The SNP heritability for individuals with schizophrenia and ADHD were $0 \%$ [ -27.5 to $27.5 \%]$ and $0.4 \%$ [ -6.6 to $7.4 \%]$, respectively.

\section{Discussion}

To our knowledge, this is the largest molecular genetic study to examine suicide attempt. By including a population-based sample, it was possible to adjust for the presence of mental disorders, hereby, addressing the possible mediating role of mental disorders. Albeit significant associations were identified by this study, the heritability estimates suggest that diagnosed mental disorders do not fully explain the genetic transmission of a suicide attempt.

\section{GWAS}

The lead SNP, rs6880062 on chromosome 5, of Model 1 is intergenic, with the closest gene being FAM114A2 (distance $=71.6 \mathrm{~kb}$ ) and has not previously been associated with suicidal behavior [15]. When intersected with GeneHancer database of enhancer regions (version: 4.6 .0 build 15) [46], one of the suggestive SNPs on chromosome 22 , rs150801052 ( $p$-value: $6.78 \times 10^{-7}$ ) was found to be within an enhancer (Enhancer ID: GH22H035858) for the proteincoding gene myoglobin, elevated levels of which has previously been suggested for monitoring in two previous cases involving an adolescent female with suicide attempt and an older adult with depression and psychosis $[50,51]$.

The enhancer was also connected to the RBFOX2 gene, which encodes an RNA-binding protein that is thought to be involved in exon splicing in the nervous system. Recently, 
Table 1 SNP showing significant or suggestive association with a suicide attempt in adjusted GWAS

\begin{tabular}{|c|c|c|c|c|c|c|c|}
\hline Model & Chromosome & Position & $\mathrm{A} 1 / \mathrm{A} 2$ & Minor allele frequency & INFO & Odds ratio $[\mathrm{CI}-95 \%]^{\mathrm{a}}$ & $p$-Value \\
\hline \multicolumn{8}{|c|}{ Model 1: Adjusted for socio-demographic conditions ${ }^{b}$} \\
\hline rs 12130410 & 1 & 81359237 & C/A & 0.0593 & 0.963265 & $0.7948 \pm 0.089964$ & $5.67 \mathrm{E}-07$ \\
\hline rs 12118384 & 1 & 81360791 & G/A & 0.0607 & 0.963841 & $0.7935 \pm 0.088984$ & $3.55 \mathrm{E}-07$ \\
\hline rs72134670 & 1 & 81361781 & AGTGT/A & 0.0592 & 0.970028 & $0.7956 \pm 0.089768$ & $5.90 \mathrm{E}-07$ \\
\hline rs114428613 & 1 & 81363409 & T/A & 0.0592 & 0.971558 & $0.7945 \pm 0.089768$ & $5.05 \mathrm{E}-07$ \\
\hline rs12122457 & 1 & 81364694 & $\mathrm{G} / \mathrm{C}$ & 0.0592 & 0.972986 & $0.7941 \pm 0.089768$ & $4.77 \mathrm{E}-07$ \\
\hline rs12119932 & 1 & 81364728 & $\mathrm{~T} / \mathrm{G}$ & 0.0592 & 0.973008 & $0.7941 \pm 0.089768$ & $4.76 \mathrm{E}-07$ \\
\hline rs12119912 & 1 & 81364903 & $\mathrm{~A} / \mathrm{G}$ & 0.0592 & 0.973055 & $0.7941 \pm 0.089768$ & $4.74 \mathrm{E}-07$ \\
\hline rs201713449 & 1 & 81365218 & G/GCA & 0.0592 & 0.973134 & $0.7940 \pm 0.089768$ & $4.72 \mathrm{E}-07$ \\
\hline rs116584414 & 1 & 81365419 & $\mathrm{~T} / \mathrm{G}$ & 0.0592 & 0.973185 & $0.7940 \pm 0.089768$ & $4.69 \mathrm{E}-07$ \\
\hline rs79479721 & 1 & 81365444 & $\mathrm{~T} / \mathrm{G}$ & 0.0592 & 0.973191 & $0.7940 \pm 0.089768$ & $4.69 \mathrm{E}-07$ \\
\hline rs115355703 & 1 & 81365722 & $\mathrm{~A} / \mathrm{C}$ & 0.0592 & 0.973267 & $0.7939 \pm 0.089768$ & $4.66 \mathrm{E}-07$ \\
\hline rs114035422 & 1 & 81366040 & $\mathrm{~A} / \mathrm{G}$ & 0.0592 & 0.973354 & $0.7939 \pm 0.089768$ & $4.64 \mathrm{E}-07$ \\
\hline rs115194926 & 1 & 81366100 & $\mathrm{G} / \mathrm{T}$ & 0.0592 & 0.973373 & $0.7939 \pm 0.089768$ & $4.63 \mathrm{E}-07$ \\
\hline rs115255447 & 1 & 81366951 & $\mathrm{~T} / \mathrm{A}$ & 0.0592 & 0.97427 & $0.7935 \pm 0.089768$ & $4.38 \mathrm{E}-07$ \\
\hline rs115410239 & 1 & 81369030 & $\mathrm{~T} / \mathrm{A}$ & 0.0592 & 0.977419 & $0.7937 \pm 0.089572$ & $4.30 \mathrm{E}-07$ \\
\hline rs12132818 & 1 & 81371930 & $\mathrm{C} / \mathrm{G}$ & 0.0592 & 0.98065 & $0.7919 \pm 0.089572$ & $3.23 \mathrm{E}-07$ \\
\hline rs72940613 & 1 & 81373376 & $\mathrm{~A} / \mathrm{G}$ & 0.0595 & 0.976727 & $0.7927 \pm 0.089376$ & $3.55 \mathrm{E}-07$ \\
\hline rs6681193 & 1 & 81374082 & $\mathrm{C} / \mathrm{T}$ & 0.0592 & 0.982108 & $0.7913 \pm 0.089572$ & $2.94 \mathrm{E}-07$ \\
\hline rs114462636 & 1 & 81375885 & $\mathrm{C} / \mathrm{T}$ & 0.0589 & 0.985097 & $0.7916 \pm 0.089572$ & $3.20 \mathrm{E}-07$ \\
\hline rs12130052 & 1 & 81379254 & $\mathrm{~T} / \mathrm{A}$ & 0.0588 & 0.989481 & $0.7932 \pm 0.089376$ & $3.80 \mathrm{E}-07$ \\
\hline rs12130531 & 1 & 81380084 & $\mathrm{C} / \mathrm{T}$ & 0.0588 & 0.989333 & $0.7932 \pm 0.089376$ & $3.77 \mathrm{E}-07$ \\
\hline rs12121366 & 1 & 81381621 & $\mathrm{~T} / \mathrm{C}$ & 0.0589 & 0.990004 & $0.7923 \pm 0.089376$ & $3.26 \mathrm{E}-07$ \\
\hline rs112409531 & 1 & 81384412 & $\mathrm{~A} / \mathrm{G}$ & 0.0588 & 0.990039 & $0.7933 \pm 0.089376$ & $3.80 \mathrm{E}-07$ \\
\hline rs12135658 & 1 & 81384847 & $\mathrm{C} / \mathrm{G}$ & 0.0594 & 0.991295 & $0.7967 \pm 0.088592$ & $5.08 \mathrm{E}-07$ \\
\hline rs17105681 & 1 & 81385360 & $\mathrm{C} / \mathrm{G}$ & 0.0596 & 0.991544 & $0.7974 \pm 0.088592$ & $5.37 \mathrm{E}-07$ \\
\hline rs12125794 & 1 & 81386101 & $\mathrm{~A} / \mathrm{C}$ & 0.0595 & 0.991884 & $0.7974 \pm 0.088592$ & $5.49 \mathrm{E}-07$ \\
\hline rs72940624 & 1 & 81387664 & $\mathrm{~T} / \mathrm{G}$ & 0.0595 & 0.992104 & $0.7972 \pm 0.088592$ & $5.36 \mathrm{E}-07$ \\
\hline rs74092049 & 1 & 81387673 & $\mathrm{~T} / \mathrm{C}$ & 0.0595 & 0.992106 & $0.7972 \pm 0.088592$ & $5.35 \mathrm{E}-07$ \\
\hline rs74092050 & 1 & 81387892 & $\mathrm{~A} / \mathrm{G}$ & 0.0596 & 0.99158 & $0.7971 \pm 0.088592$ & $5.12 \mathrm{E}-07$ \\
\hline rs17105699 & 1 & 81391541 & $\mathrm{~A} / \mathrm{G}$ & 0.0589 & 0.991587 & $0.7928 \pm 0.08918$ & $3.36 \mathrm{E}-07$ \\
\hline rs74092063 & 1 & 81393160 & $\mathrm{G} / \mathrm{A}$ & 0.059 & 0.991599 & $0.7923 \pm 0.08918$ & $3.05 \mathrm{E}-07$ \\
\hline rs7548691 & 1 & 81396755 & $\mathrm{G} / \mathrm{A}$ & 0.0591 & 0.992042 & $0.7920 \pm 0.08918$ & $2.91 \mathrm{E}-07$ \\
\hline rs17105728 & 1 & 81398266 & $\mathrm{~T} / \mathrm{C}$ & 0.0589 & 0.992018 & $0.7917 \pm 0.08918$ & $2.89 \mathrm{E}-07$ \\
\hline rs12133801 & 1 & 81401114 & G/A & 0.0589 & 0.993456 & $0.7919 \pm 0.08918$ & $2.89 \mathrm{E}-07$ \\
\hline rs79780846 & 1 & 81419288 & G/A & 0.0588 & 0.987839 & $0.7911 \pm 0.089572$ & $2.83 \mathrm{E}-07$ \\
\hline rs 12139190 & 1 & 81420151 & $\mathrm{~A} / \mathrm{C}$ & 0.0587 & 0.987233 & $0.7913 \pm 0.089572$ & $3.05 \mathrm{E}-07$ \\
\hline rs72940689 & 1 & 81428767 & G/A & 0.0586 & 0.978883 & $0.7897 \pm 0.09016$ & $2.78 \mathrm{E}-07$ \\
\hline rs 2560038 & 5 & 153272968 & G/A & 0.3232 & 0.993039 & $0.8960 \pm 0.04214$ & $3.10 \mathrm{E}-07$ \\
\hline rs 1593827 & 5 & 153280893 & G/A & 0.3112 & 0.995496 & $0.8914 \pm 0.042532$ & $1.17 \mathrm{E}-07$ \\
\hline rs898709 & 5 & 153286964 & $\mathrm{~A} / \mathrm{G}$ & 0.3117 & 1 & $0.8929 \pm 0.042336$ & $1.66 \mathrm{E}-07$ \\
\hline rs 1870738 & 5 & 153287549 & $\mathrm{~T} / \mathrm{A}$ & 0.3126 & 0.998605 & $0.8921 \pm 0.042336$ & $1.31 \mathrm{E}-07$ \\
\hline rs 2085865 & 5 & 153290253 & $\mathrm{G} / \mathrm{A}$ & 0.3121 & 0.998881 & $0.8913 \pm 0.042336$ & $1.06 \mathrm{E}-07$ \\
\hline rs2035099 & 5 & 153290835 & C/A & 0.3121 & 0.998768 & $0.8914 \pm 0.042336$ & $1.07 \mathrm{E}-07$ \\
\hline rs 7726518 & 5 & 153293565 & G/A & 0.3123 & 0.998245 & $0.8914 \pm 0.042336$ & $1.06 \mathrm{E}-07$ \\
\hline rs 2126160 & 5 & 153294271 & $\mathrm{C} / \mathrm{T}$ & 0.3123 & 0.99833 & $0.8914 \pm 0.042336$ & $1.07 \mathrm{E}-07$ \\
\hline rs7732031 & 5 & 153294900 & $\mathrm{~A} / \mathrm{G}$ & 0.3123 & 0.998254 & $0.8914 \pm 0.042336$ & $1.08 \mathrm{E}-07$ \\
\hline
\end{tabular}


Table 1 (continued)

\begin{tabular}{|c|c|c|c|c|c|c|c|}
\hline Model & Chromosome & Position & $\mathrm{A} 1 / \mathrm{A} 2$ & Minor allele frequency & INFO & Odds ratio $[\mathrm{CI}-95 \%]^{\mathrm{a}}$ & $p$-Value \\
\hline rs 1599408 & 5 & 153296017 & $\mathrm{C} / \mathrm{T}$ & 0.3125 & 0.998001 & $0.8927 \pm 0.042336$ & $1.53 \mathrm{E}-07$ \\
\hline rs 1599409 & 5 & 153296064 & $\mathrm{C} / \mathrm{A}$ & 0.3123 & 0.998137 & $0.8915 \pm 0.042336$ & $1.10 \mathrm{E}-07$ \\
\hline rs1599410 & 5 & 153296073 & $\mathrm{C} / \mathrm{T}$ & 0.3123 & 0.998137 & $0.8915 \pm 0.042336$ & $1.10 \mathrm{E}-07$ \\
\hline rs6880461 & 5 & 153298024 & $\mathrm{G} / \mathrm{A}$ & 0.3138 & 0.997715 & $0.8911 \pm 0.042336$ & $9.52 \mathrm{E}-08$ \\
\hline rs6880062 & 5 & 153298025 & $\mathrm{~A} / \mathrm{G}$ & 0.3107 & 0.989144 & $0.8884 \pm 0.042728$ & $5.44 \mathrm{E}-08$ \\
\hline rs 2614123 & 5 & 153300215 & $\mathrm{C} / \mathrm{T}$ & 0.3139 & 0.996726 & $0.8914 \pm 0.042336$ & $1.06 \mathrm{E}-07$ \\
\hline rs7862648 & 9 & 18290857 & $\mathrm{~A} / \mathrm{G}$ & 0.2187 & 0.991736 & $1.1212 \pm 0.045864$ & $9.80 \mathrm{E}-07$ \\
\hline rs112595860 & 12 & 32640591 & $\mathrm{C} / \mathrm{G}$ & 0.2172 & 0.931883 & $0.8798 \pm 0.049784$ & $4.55 \mathrm{E}-07$ \\
\hline rs113067218 & 12 & 32641482 & $\mathrm{CT} / \mathrm{C}$ & 0.2174 & 0.932194 & $0.8814 \pm 0.049784$ & $6.54 \mathrm{E}-07$ \\
\hline rs10506086 & 12 & 32642659 & $\mathrm{C} / \mathrm{T}$ & 0.2162 & 0.930623 & $0.8808 \pm 0.04998$ & $6.17 \mathrm{E}-07$ \\
\hline rs4810824 & 20 & 47193708 & $\mathrm{G} / \mathrm{C}$ & 0.6268 & 0.959962 & $0.8994 \pm 0.040376$ & $2.65 \mathrm{E}-07$ \\
\hline rs4809706 & 20 & 47193719 & $\mathrm{~A} / \mathrm{G}$ & 0.6273 & 0.958887 & $0.8987 \pm 0.040376$ & $2.19 \mathrm{E}-07$ \\
\hline rs6125386 & 20 & 47196367 & $\mathrm{~A} / \mathrm{G}$ & 0.6323 & 0.971916 & $0.9042 \pm 0.04018$ & $9.42 \mathrm{E}-07$ \\
\hline rs6019297 & 20 & 47197230 & $\mathrm{C} / \mathrm{T}$ & 0.625 & 0.958847 & $0.9002 \pm 0.040376$ & $3.34 \mathrm{E}-07$ \\
\hline rs 150801052 & 22 & 36255928 & AT/A & 0.0167 & 0.677581 & $1.5076 \pm 0.161896$ & $6.78 \mathrm{E}-07$ \\
\hline \multicolumn{8}{|c|}{ Model 2: Adjusted for socio-demographic conditions and mental disorders ${ }^{c}$} \\
\hline rs 4053798 & 6 & 85943189 & $\mathrm{~A} / \mathrm{C}$ & 0.9945 & 0.926872 & $0.5418 \pm 0.242844$ & $7.60 \mathrm{E}-07$ \\
\hline rs76426299 & 8 & 58350711 & G/A & 0.0189 & 0.556548 & $1.6189 \pm 0.191688$ & $8.40 \mathrm{E}-07$ \\
\hline rs7862648 & 9 & 18290857 & $\mathrm{~A} / \mathrm{G}$ & 0.2187 & 0.991736 & $1.1281 \pm 0.047824$ & $7.82 \mathrm{E}-07$ \\
\hline rs 4810824 & 20 & 47193708 & $\mathrm{G} / \mathrm{C}$ & 0.6268 & 0.959962 & $0.8884 \pm 0.04214$ & $3.56 \mathrm{E}-08$ \\
\hline rs4809706 & 20 & 47193719 & $\mathrm{~A} / \mathrm{G}$ & 0.6273 & 0.958887 & $0.8875 \pm 0.04214$ & $2.80 \mathrm{E}-08$ \\
\hline rs6019294 & 20 & 47194199 & G/A & 0.5818 & 0.974655 & $0.9014 \pm 0.04116$ & $7.68 \mathrm{E}-07$ \\
\hline rs6066764 & 20 & 47194229 & $\mathrm{C} / \mathrm{A}$ & 0.5759 & 0.971501 & $0.8994 \pm 0.04116$ & $4.57 \mathrm{E}-07$ \\
\hline rs6066765 & 20 & 47194232 & $\mathrm{G} / \mathrm{C}$ & 0.5759 & 0.971509 & $0.8994 \pm 0.04116$ & $4.57 \mathrm{E}-07$ \\
\hline rs6019295 & 20 & 47194750 & $\mathrm{G} / \mathrm{A}$ & 0.5841 & 0.984819 & $0.9011 \pm 0.040964$ & $6.42 \mathrm{E}-07$ \\
\hline rs6122700 & 20 & 47196231 & $\mathrm{~T} / \mathrm{C}$ & 0.6901 & 0.970105 & $0.8969 \pm 0.043512$ & $9.10 \mathrm{E}-07$ \\
\hline rs6125386 & 20 & 47196367 & $\mathrm{~A} / \mathrm{G}$ & 0.6323 & 0.971916 & $0.8947 \pm 0.041944$ & $2.03 \mathrm{E}-07$ \\
\hline rs6012487 & 20 & 47196557 & $\mathrm{G} / \mathrm{C}$ & 0.6317 & 0.972012 & $0.8953 \pm 0.041944$ & $2.36 \mathrm{E}-07$ \\
\hline rs4810826 & 20 & 47196647 & $\mathrm{~T} / \mathrm{C}$ & 0.6311 & 0.972755 & $0.8950 \pm 0.041944$ & $2.13 \mathrm{E}-07$ \\
\hline rs4810827 & 20 & 47196809 & $\mathrm{~T} / \mathrm{C}$ & 0.6314 & 0.971384 & $0.8951 \pm 0.041944$ & $2.29 \mathrm{E}-07$ \\
\hline rs6019297 & 20 & 47197230 & $\mathrm{C} / \mathrm{T}$ & 0.625 & 0.958847 & $0.8893 \pm 0.04214$ & $4.71 \mathrm{E}-08$ \\
\hline
\end{tabular}

${ }^{a}$ Odds ratios were calculated with respect to A2

${ }^{b}$ Model 1 was adjusted for gender, number of years under observation over the age of 15, and first 10 principal components of genetic ancestry ${ }^{c}$ Model 2 was adjusted for gender, number of years under follow-up being (aged $\geq 15$ years), first 10 principal components of genetic ancestry, diagnosis of any mental disorder as well as diagnosis of schizophrenia, bipolar disorders, affective disorders, autism spectrum disorders, anorexia, and ADHD

this gene has been highlighted in a GWAS for major depression conducted by the Psychiatric Genomics Consortium, which includes the iPSYCH dataset [52]. Both connections were supported by evidence from $\mathrm{C}-\mathrm{HiC}$ interactions.

The lead SNP identified on chromosome 20 in Model 2, rs4809706, is also intergenic with the nearest gene being PREXI (distance $=47 \mathrm{~kb}$ ), which has been associated with depression and autism-like behavior [53]. An intersection with GeneHancer database did not reveal any associations with known enhancers or promoters.
By querying the GWAS catalog and PubMed, we attempted to replicate 40 SNPs associated to suicidal ideation or suicide attempt in six previous GWAS studies $[13,14,54-59]$, We were unable to replicate either of the genome-wide significant loci identified [13, 58]. Nevertheless, one of the suggestive associations on chromosome 11 [13], rs10437629 showed significance in both models 1 $(p=0.029)$ and $2(p=0.03)$ in the current data (Supplementary Table 3$)$.

In the association study comparing individuals with major depressive disorders and suicide attempts to healthy 


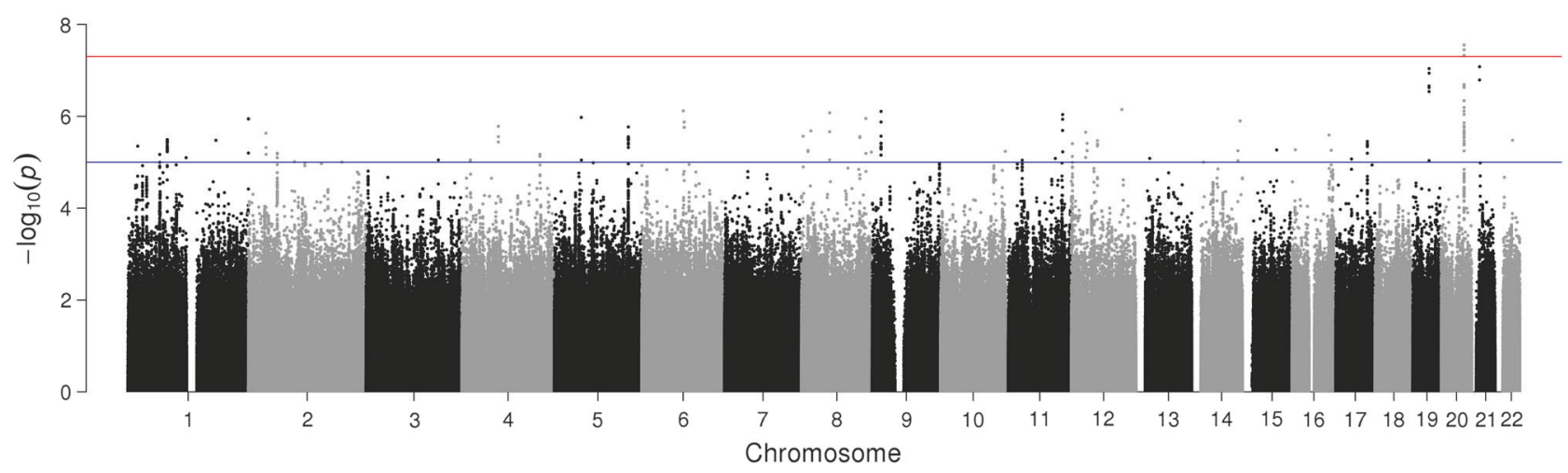

Fig. 2 Manhattan plot of genome-wide association study (GWAS) of suicide attempt adjusted for: gender, number of years under follow-up being (aged $\geq 15$ years), first 10 principal components of genetic ancestry, diagnosis of any mental disorder as well as diagnosis of schizophrenia, bipolar disorders, affective disorders, autism spectrum disorders, anorexia, and ADHD (Model 2). Note: The red line marks the threshold of $p=5 \times 10^{-8}$ for significant associations while the blue line marks the threshold of $p=5 \times 10^{-6}$ for suggestive associations controls, the lead SNP, rs4554696, is in the intronic region of the gene $P D E 4 B$, which has previously been implicated in schizophrenia and bipolar disorders [60, 61]. Studies in Japanese populations have associated $P D E 4 B$ to panic disorders and major depression [62, 63]. A gene expression analysis from the GTEx portal (release v7) [64] revealed $P D E 4 B$ being highly expressed in brain-related tissues (Supplementary Figure 2). An intersection with the GeneHancer database showed that four tag SNPs (LD: $r^{2}>0.8$ with the lead SNP) rs12062815 ( $p$-value: $9.22 \times 10^{-9}$ ), rs12062901 ( $p$-value: $\left.7.8 \times 10^{-9}\right)$, rs1318475 ( $p$-value: $\left.7.244 \times 10^{-9}\right)$, and rs34482581 ( $p$-value: $\left.6.994 \times 10^{-9}\right)$ fall within an enhancer for the gene $P D E 4 B$ with the following brain tissue annotations: anterior caudate, cingulate gyrus, inferior temporal lobe, hippocampus middle (Enhancer ID: GH01H065961). The connection to the gene $P D E 4 B$ was further validated by $\mathrm{C}-\mathrm{HiC}$ interaction. Interestingly, this locus has not been observed to achieve genome-wide significance in previous studies of large-sample GWAS of major depressive disorder [52]; indicating that suicidal behavior could possibly be utilized as a secondary phenotype to explore severity within major depressive disorder. Behavioral and neurochemical characterization of $P D E 4 B$ in an animal model revealed the $P D E 4 B$-knockout mice to have significantly reduced pre-pulse inhibition, decreased spontaneous locomotor activity, and enhanced response to amphetamine [65]. Additionally, PDE4B-deficient mice display anxiogenic-like behavior [66], further supporting the role of the $P D E 4 B$ gene in the etiology of mental disorders.

Various causal pathways have been suggested [26]. While previous studies have identified loci associated with suicidal attempts in clinical or relatively small population samples [11], our findings add significant support to the role of genes in the etiology of suicidal behavior. Liability for mental disorders, such as affective disorders or borderline personality disorders, may be inherited and explain the link to suicidal behavior [20, 26, 27]. Secondly, the relationship between genes and suicidal behavior may be mediated by behavioral traits, such as impulsive and impulsiveaggressive behaviors [67, 68]. Furthermore, environmental factors, such as stressful life events and social constraints, might interact with genetic factors [27].

\section{Heritability}

A heritability of $4.6 \%$ is substantially lower than reported in the family and twin studies [9]. However, this type of studies cannot fully account for social contamination through social role models, social heritages, such as living conditions, and other shared environmental factors [69]. The GCTA estimates provide a lower bound estimate for genetic heritability, as not all genetic variation can be explained by genotyped SNPs [70]. Still, it is interesting that a heritability of $1.9 \%$ was maintained when adjusting for the presence of any and specific mental disorders; this estimate is also lower than the $17.4 \%$ noted in observational studies [8, 71]. The reduction from 4.6 to $1.9 \%$ indicates that parts of the genetic transmission might be explained through mental disorders.

Schizophrenia has been linked to an absolute suicide risk of $6.5 \%$ [19]. Nevertheless, a SNP heritability close to zero might be related to the relatively small number of individuals suffering from schizophrenia with a suicide attempt. Alternative explanations could be that genetic heterogeneity of suicide attempt is explained in part by diagnosed mental 
Fig. 3 Region plot of the association evidence in gene $P D E 4 B$ in the chromosome $1 \mathrm{p} 31.3$ in a sub-group analysis of cases with affective disorders vs. healthy controls (hg19, LocusZoom viewer) [76].

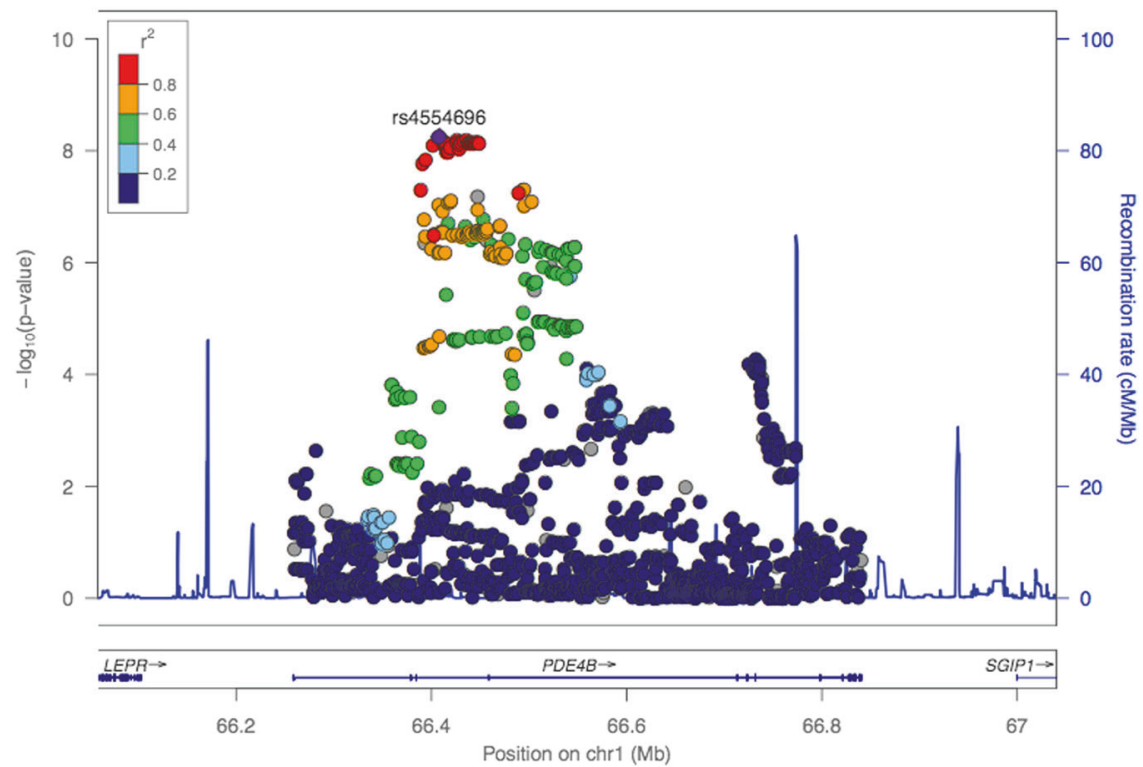

disorders; or in conditions, such as schizophrenia, the genetic factors explaining suicide attempt are not distinct from those genetic factors increasing the risk for the disorder itself. Interestingly, a polygenic overlap between schizoaffective disorders and suicide attempt has previously been suggested [72]. The highest heritability was found for autism spectrum disorders; indicating that SNP heritability accounted for up to $10 \%$ of suicide attempts. This has not previously been documented and future studies might gain insights by assessing mental disorders separately.

\section{Strengths and limitations}

The Danish Newborn Screening Biobank presents an almost complete coverage and a validated approach for DNA extraction and genotyping was used [27, 35]. Furthermore, complete hospital records of psychiatric inpatients for the entire study period were available while data on emergency department and out-patients were included in 1995 when the oldest birth cohorts were 13 years of age [29], hence, keeping the probability of selection bias low. While previous studies had to rely on self-reported data [73], the phenotype was based on hospital records and measured consistently for all subjects. Using a large population-based sample with limited population heterogeneity adds additional strengths to this study. Furthermore, the inclusion of healthy individuals allowed for stratification by mental disorders [11].

Limitations should be acknowledged. About half of the genotyped SNPs were excluded due to the low-frequency exome SNPs in the iPSYCH array design [31]. Due to the sample acquisition, our findings pertain to suicide attempts among individuals below the age of 32 years; i.e., the age segment with the highest rates of suicide attempt [74]. Suicide attempt is under-recorded in Danish hospitals [74], and a substantial proportion of individuals do not seek hospital care after a suicide attempt [75]. By including a validated, wider proxy, any bias would likely render our estimates conservative; yet, the possibility of false positives cannot be excluded. For reasons of data availability, it was not feasible to examine different methods separately. Hospital-based diagnoses served as a proxy for severe mental disorders; while it is likely that the severe cases of mental disorders will be seen at the hospital, less severe cases might be missed. Also, we did not account for changes in the status of mental disorders over time. It would have been desirable to account for a range of different covariates, such as physical comorbidity and stressful life events, however, this was not feasible in this study.

\section{Conclusion}

This large, population-based GWAS of young adults identified SNPs with novel significant associations to suicide attempt while accounting for diagnoses of mental disorders. An association study comparing individuals with affective disorder and attempted suicide to healthy controls revealed a novel association in the intronic region of the gene PDE4B. Heritability estimates indicated that variation in a suicide attempt is associated with the genetic variation and that this association is, partially but perhaps not entirely, explained through mental disorders.

Acknowledgements The Lundbeck Foundation and the Novo Nordisk Foundation had no role in the design and conduct of the study; 
Table 2 SNP heritability with respect to gender and mental disorders

\begin{tabular}{|c|c|c|c|c|c|c|}
\hline & $\begin{array}{l}\text { Suicide attempt } \\
n(\%)^{\mathrm{a}}\end{array}$ & $\begin{array}{l}\text { Control group } \\
n(\%)^{\mathrm{a}}\end{array}$ & $\begin{array}{l}\text { Model } 1^{\text {b }} \\
h^{2} \text { [CI-95\%] }\end{array}$ & $p$-Value & $\begin{array}{l}\text { Model } 2^{\mathrm{c}} \\
h^{2}[\text { CI-95\%] }\end{array}$ & $p$-Value \\
\hline All & $6024(100.0)$ & $44,240(100.0)$ & $4.6[2.9-6.3]$ & $<0.0001$ & $1.9[0.3-3.5]$ & 0.008 \\
\hline \multicolumn{7}{|l|}{ Gender } \\
\hline Males & $1837(30.5)$ & $22,735(51.4)$ & $5.3[2.4-8.2]$ & 0.0001 & $2.8[-0.1$ to 5.7$]$ & 0.026 \\
\hline Females & $4187(69.5)$ & $21,505(48.6)$ & $4.7[1.9-7.5]$ & 0.0003 & $1.9[-0.7$ to 4.5$]$ & 0.064 \\
\hline \multicolumn{7}{|l|}{ Mental disorders } \\
\hline No diagnosis & $132(2.2)$ & $13,294(30.1)$ & $3.3[-1.0$ to 7.6$]$ & 0.063 & & \\
\hline Any diagnosis & $5892(97.8)$ & $30,946(70.0)$ & $2.8[0.7-4.9]$ & 0.0027 & & \\
\hline \multicolumn{7}{|l|}{ Diagnosis } \\
\hline Schizophrenia & $581(9.6)$ & 1579 (3.6) & $0.0[-27.5$ to 27.5$]$ & 0.50 & & \\
\hline Bipolar $^{\mathrm{d}}$ & $302(5.0)$ & $911(2.1)$ & $16.3[-32.0$ to 64.6$]$ & 0.254 & & \\
\hline Affective disorders & $4302(71.4)$ & $14,935(33.8)$ & $5.6[1.9-9.3]$ & 0.001 & & \\
\hline Autism & $402(6.7)$ & $7008(15.8)$ & $9.6[1.1-18.1]$ & 0.0115 & & \\
\hline Anorexia & $1254(20.8)$ & $7866(17.8)$ & $10.6[-10.5$ to 31.7$]$ & 0.148 & & \\
\hline ADHD & $350(5.8)$ & $2389(5.4)$ & $0.4[-6.6$ to 7.4$]$ & 0.45 & & \\
\hline
\end{tabular}

${ }^{a}$ Additional cases and controls were excluded from the GCTA analysis due to further adjustment for kinship by accounting for cryptic relatedness

${ }^{b}$ Model 1 was adjusted for gender, number of years under observation over the age of 15 , and first 10 principal components of genetic ancestry. The $\mathrm{h} 2$ estimates are on the observed scale.

${ }^{c}$ Model 2 was adjusted for gender, number of years under follow-up being (aged $\geq 15$ years), first 10 principal components of genetic ancestry, diagnosis of any mental disorder as well as diagnosis of schizophrenia, bipolar disorders, affective disorders, autism spectrum disorders, anorexia, and ADHD. The h2 estimates are on the observed scale.

${ }^{\mathrm{d}}$ Bipolar disorders (ICD: F30-F31) was a subset of affective disorders (ICD: F30-F39)

collection, management, analysis, and interpretation of the data; preparation, review, or approval of the manuscript; and decision to submit the manuscript for publication.

Funding The study was supported by the Lundbeck Foundation (Grant numbers R102-A9118 and R155-2014-1724). Furthermore, this research has been conducted using the Danish National Biobank resource supported by the Novo Nordisk Foundation and the Lundbeck Foundation. Additionally, Dr. Thompson was supported by NIH 1R01GM104400.

Author contributions Appadurai, Dr. Wang, and Dr. Thompson had full access to all the data in the study and assume responsibility for the integrity of the data and the accuracy of the data analysis. Study concept and design: Erlangsen, Agerbo, Nordentoft, Thompson, Mors, Wang, Appadurai, Turecki, Mortensen, and Werge. Acquisition, analysis, or interpretation of data: All authors. Drafting of the manuscript: Erlangsen, Agerbo, Appadurai, Nordentoft, and Turecki. Critical revision of the manuscript for important intellectual content: All authors. Statistical analysis: Appadurai, Wang, Thompson, Agerbo, Schork, Nudel, Erlangsen, and Turecki. Obtained funding: Nordentoft, Mortensen, Werge, Mors, and Hougaard. Administrative, technical, or material support: Thompson, Agerbo, Wang, Appadurai, Nordentoft, Mortensen, Werge, Mors, Hougaard, Bækvad-Hansen, and Bybjerg-Grauholm. Supervision: Agerbo, Thompson, Nordentoft, Turecki, and Mors.

\section{Compliance with ethical standards}

Conflict of interest The authors declare that they have no conflict of interest.

\section{References}

1. Nock MK, Borges G, Bromet EJ, Cha CB, Kessler RC, Lee S. Suicide and suicidal behavior. Epidemiol Rev. 2008;30:133-54.

2. World Health Organization. Preventing suicide-a global imperative. Geneva: WHO; 2014.

3. Agerbo E, Nordentoft M, Mortensen PB. Familial, psychiatric, and socioeconomic risk factors for suicide in young people: nested case-control study. BMJ. 2002;325:74.

4. Runeson B, Asberg M. Family history of suicide among suicide victims. Am J Psychiatry. 2003;160:1525-6.

5. Tidemalm D, Runeson B, Waern M, Frisell T, Carlström E, Lichtenstein P, et al. Familial clustering of suicide risk: a total population study of 11.4 million individuals. Psychol Med. 2011; 41:2527-34.

6. Qin P, Agerbo E, Mortensen PB. Suicide risk in relation to socioeconomic, demographic, psychiatric and familial factors: a national register-based study of all suicides in Denmark, 1981-97. Am J Psychiatry. 2003;160:765-72.

7. Agerbo E, Qin P, Mortensen PB. Psychiatric illness, socioeconomic status, and marital status in people committing suicide: a matched case-sibling-control study. J Epidemiol Community Health. 2006;60:776-81.

8. Statham DJ, Heath AC, Madden PA, Bucholz KK, Bierut L, Dinwiddie SH, et al. Suicidal behaviour: an epidemiological and genetic study. Psychol Med. 1998;28:839-55.

9. Turecki G, Brent DA. Suicide and suicidal behaviour. Lancet. 2016;387:1227-39.

10. Wender PH, Kety SS, Rosenthal D, Schulsinger F, Ortmann J, Lunde I. Psychiatric disorders in the biological and adoptive 
families of adopted individuals with affective disorders. Arch Gen Psychiatry. 1986;43:923-9.

11. Sokolowski M, Wasserman J, Wasserman D. Genome-wide association studies of suicidal behaviors: a review. Eur Neuropsychopharmacol. 2014;24:1567-77.

12. Brezo J, Bureau A, Merette C, Jomphe V, Barker ED, Vitaro F, et al. Differences and similarities in the serotonergic diathesis for suicide attempts and mood disorders: a 22-year longitudinal geneenvironment study. Mol Psychiatry. 2010;15:831-43.

13. Willour VL, Seifuddin F, Mahon PB, Jancic D, Pirooznia M, Steele $\mathrm{J}$, et al. A genome-wide association study of attempted suicide. Mol Psychiatry. 2012;17:433-44.

14. Perlis RH, Huang J, Purcell S, Fava M, Rush AJ, Sullivan PF, et al. Genome-wide association study of suicide attempts in mood disorder patients. Am J Psychiatry. 2010;167:1499-507.

15. Sokolowski M, Wasserman J, Wasserman D. An overview of the neurobiology of suicidal behaviors as one meta-system. Mol Psychiatry. 2015;20:56-71.

16. Baldessarini RJ, Hennen J. Genetics of suicide: an overview. Harv Rev Psychiatry. 2004;12:1-13.

17. Qin P. The impact of psychiatric illness on suicide: differences by diagnosis of disorders and by sex and age of subjects. J Psychiatr Res. 2011;45:1445-52.

18. Hawton K, van Heeringen K. Suicide. Lancet. 2009;373:1372-81.

19. Nordentoft M, Mortensen PB, Pedersen CB. Absolute risk of suicide after first hospital contact in mental disorder. Arch Gen Psychiatry. 2011;68:1058-64.

20. Sullivan PF, Neale MC, Kendler KS. Genetic epidemiology of major depression: review and meta-analysis. Am J Psychiatry. 2000;157:1552-62.

21. Cross-Disorder Group of the Psychiatric Genomics Consortium. Identification of risk loci with shared effects on five major psychiatric disorders: a genome-wide analysis. Lancet. 2013;381:1371-9.

22. Brent DA, Bridge J, Johnson BA, Connolly J. Suicidal behavior runs in families. A controlled family study of adolescent suicide victims. Arch Gen Psychiatry. 1996;53:1145-52.

23. McGirr A, Alda M, Seguin M, Cabot S, Lesage A, Turecki G. Familial aggregation of suicide explained by cluster B traits: a three-group family study of suicide controlling for major depressive disorder. Am J Psychiatry. 2009;166:1124-34.

24. Prentice RL. A case-cohort design for epidemiologic cohort studies and disease prevention trials. Biometrika. 1986;73:1-11.

25. Erlangsen A, Fedyszyn I. Danish nationwide registers for public health and health-related research. Scand J Public Health. 2015;43:333-9.

26. Pedersen CB. The Danish Civil Registration System. Scand J Public Health Suppl. 2011;39:22-5.

27. Norgaard-Pedersen B, Hougaard DM. Storage policies and use of the Danish Newborn Screening Biobank. J Inherit Metab Dis. 2007;30:530-6.

28. Nørgaard-Pedersen B, Simonsen H. Biological specimen banks in neonatal screening. Acta Paediatr Suppl. 1999;88:106-9.

29. Mors O, Perto GP, Mortensen PB. The Danish Psychiatric Central Research Register. Scand J Public Health Suppl. 2011;39:54-7.

30. Lynge E, Sandegaard JL, Rebolj M. The Danish National Patient Register. Scand J Public Health Suppl. 2011;39:30-3.

31. Pedersen CB, Bybjerg-Grauholm J, Pedersen MG, Grove J, Agerbo E, Baekvad-Hansen M, et al. The iPSYCH2012 casecohort sample: new directions for unravelling genetic and environmental architectures of severe mental disorders. Mol Psychiatry. 2017;23:6-14.

32. International statistical classification of diseases and related health problems, 10th revision. Geneva: World Health Organization; 2007. Available from: http://apps.who.int/classifications/apps/icd/ icd10online/ [updated 11/24/2009].
33. Laursen TM, Trabjerg BB, Mors O, Borglum AD, Hougaard DM, Mattheisen M, et al. Association of the polygenic risk score for schizophrenia with mortality and suicidal behavior-a Danish population-based study. Schizophr Res. 2017;184: 122-7.

34. Pedersen MG, Mortensen P, Norgaard-Pedersen B, Postolache TT. Toxoplasma gondii infection and self-directed violence in mothers. Arch Gen Psychiatry. 2012;69:1123-30.

35. Hollegaard MV, Grauholm J, Borglum A, Nyegaard M, NorgaardPedersen B, Orntoft T, et al. Genome-wide scans using archived neonatal dried blood spot samples. BMC Genomics. 2009; 10:297.

36. Hollegaard MV, Sørensen KM, Petersen HK, Arnardottir MB, Nørgaard-Pedersen B, Thorsen P, et al. Whole genome amplification and genetic analysis after extraction of proteins from dried blood spots. Clin Chem. 2007;53:1161-2.

37. Agerbo E, Mortensen PB, Wiuf C, Pedersen MS, McGrath J, Hollegaard MV, et al. Modelling the contribution of family history and variation in single nucleotide polymorphisms to risk of schizophrenia: a Danish national birth cohort-based study. Schizophr Res. 2012;134:246-52.

38. O'Connell J, Sharp K, Shrine N, Wain L, Hall I, Tobin M, et al. Haplotype estimation for biobank-scale data sets. Nat Genet. 2016;48:817-20.

39. Howie BN, Donnelly P, Marchini J. A flexible and accurate genotype imputation method for the next generation of genomewide association studies. PLoS Genet. 2009;5:e1000529.

40. Price AL, Patterson NJ, Plenge RM, Weinblatt ME, Shadick NA, Reich D. Principal components analysis corrects for stratification in genome-wide association studies. Nat Genet. 2006;38: 904-9.

41. Manichaikul A, Mychaleckyj JC, Rich SS, Daly K, Sale M, Chen W-M. Robust relationship inference in genome-wide association studies. Bioinformatics. 2010;26:2867-73.

42. Schork AJ, Won H, Appadurai V, Nudel R, Gandal M, Delaneau $\mathrm{O}$, et al. A genome-wide association study for shared risk across major psychiatric disorders in a nation-wide birth cohort implicates fetal neurodevelopment as a key mediator. bioRxivorg. 2017.

43. Chang CC, Chow C, Tellier L, Vattikuti S, Purcell S, Lee J. Second generation PLINK: rising to the challenge of larger and richer datasets. GigaScience; 2015;4:7.

44. Turner S. qqman: an R package for visualizing GWAS results using Q-Q and Manhattan plots.

45. Yang J, Lee SH, Goddard ME, Visscher PM. GCTA: a tool for genome-wide complex trait analysis. Am J Hum Genet. 2011;88:76-82.

46. Fishilevich S, Nudel R, Rappaport N, Hadar R, Plaschkes I, Iny Stein T, et al. GeneHancer: genome-wide integration of enhancers and target genes in GeneCards. Database (Oxford). 2017;2017: bax028.

47. UCSC Genome Browser Database. Santa Cruz, USA: University of California. Available from: https://genome.ucsc.edu/cgi-bin/ hgLiftOver [cited 2018].

48. Quinlan AR. BEDTools: the Swiss-Army tool for genome feature analysis. Curr Protoc Bioinform. 2002. https://doi.org/10.1002/ 0471250953.bi1112s47.

49. Lonsdale J, Thomas J, Salvatore M, Phillips R, Lo E, Shad S, et al. The Genotype-Tissue Expression (GTEx) project. Nat Genet. 2013;45:580.

50. Gupta S, Racaniello AA. Neuroleptic malignant syndrome associated with amoxapine and lithium in an older adult. Ann Clin Psychiatry. 2000;12:107-9.

51. Tesfaye H, Prusa R, Doupovcova J. [Hypokalaemia in a suicide attempt of an adolescent girl]. Casopís Lékarư Českých. 2008;147:333-6. 
52. Wray NR, Sullivan PF. Genome-wide association analyses identify 44 risk variants and refine the genetic architecture of major depression. Nat Genet. 2018;50:668-81.

53. Li J, Chai A, Wang L, Ma Y, Wu Z, Yu H, et al. Synaptic P-Rex1 signaling regulates hippocampal long-term depression and autismlike social behavior. Proc Natl Acad Sci USA. 2015;112:E6964-72.

54. Mullins N, Perroud N, Uher R, Butler AW, Cohen-Woods S, Rivera M, et al. Genetic relationships between suicide attempts, suicidal ideation and major psychiatric disorders: a genome-wide association and polygenic scoring study. Am J Med Genet B Neuropsychiatr Genet. 2014;165:428-37.

55. Galfalvy H, Haghighi F, Hodgkinson C, Goldman D, Oquendo MA, Burke A, et al. A genome-wide association study of suicidal behavior. Am J Med Genet B Neuropsychiatr Genet. 2015;168:557-63.

56. Zai CC, Gonçalves VF, Tiwari AK, Gagliano SA, Hosang G, De Luca V, et al. A genome-wide association study of suicide severity scores in bipolar disorder. J Psychiatr Res. 2015;65:23-9.

57. Perroud N, Uher R, Ng M, Guipponi M, Hauser J, Henigsberg N, et al. Genome-wide association study of increasing suicidal ideation during antidepressant treatment in the GENDEP project. Pharm J. 2012;12:68.

58. Stein MB, Ware EB, Mitchell C, Chen CY, Borja S, Cai T, et al. Genome wide association studies of suicide attempts in US soldiers. Am J Med Genet B Neuropsychiatr Genet. 2017;174:786-97.

59. GWAS Catalog. Bethesda, MD, USA: National Human Genome Research Institute. Available from: https://www.ebi.ac.uk/gwas/ home [cited 2018].

60. Feng Y, Cheng D, Zhang C, Li Y, Zhang Z, Wang J, et al. Association of PDE4B polymorphisms with susceptibility to schizophrenia: a meta-analysis of case-control studies. PLoS ONE. 2016;11:e0147092.

61. McDonald ML, MacMullen C, Liu DJ, Leal SM, Davis RL. Genetic association of cyclic AMP signaling genes with bipolar disorder. Transl Psychiatry. 2012;2:e169.

62. Otowa T, Kawamura Y, Sugaya N, Yoshida E, Shimada T, Liu X, et al. Association study of PDE4B with panic disorder in the Japanese population. Prog Neuropsychopharmacol Biol Psychiatry. 2011;35:545-9.

63. Iga J, Ueno S, Yamauchi $\mathrm{K}$, Numata S, Tayoshi-Shibuya S, Kinouchi S, et al. The Val66Met polymorphism of the brain- derived neurotrophic factor gene is associated with psychotic feature and suicidal behavior in Japanese major depressive patients. Am J Med Genet B Neuropsychiatr Genet. 2007;144B: 1003-6.

64. GTEx Consortium. Genetic effects on gene expression across human tissues. Nature. 2017;550:204-13.

65. Siuciak JA, McCarthy SA, Chapin DS, Martin AN. Behavioral and neurochemical characterization of mice deficient in the phosphodiesterase-4B (PDE4B) enzyme. Psychopharmacology (Berl). 2008;197:115-26.

66. Zhang H-T, Huang Y, Masood A, Stolinski LR, Li Y, Zhang L, et al. Anxiogenic-like behavioral phenotype of mice deficient in phosphodiesterase 4B (PDE4B). Neuropsychopharmacology. 2007;33:1611.

67. Turecki G. The molecular bases of the suicidal brain. Nat Rev Neurosci. 2014;15:802-16.

68. Turecki G. Suicidal behavior: is there a genetic predisposition? Bipolar Disord. 2001;3:335-49.

69. Brent DA, Mann JJ. Family genetic studies, suicide, and suicidal behavior. Am J Med Genet C Semin Med Genet. 2005;133C: 13-24.

70. Manolio TA, Collins FS, Cox NJ, Goldstein DB, Hindorff LA, Hunter DJ, et al. Finding the missing heritability of complex diseases. Nature. 2009;461:747-53.

71. Mann JJ, Arango VA, Avenevoli S, Brent DA, Champagne FA, Clayton P, et al. Candidate endophenotypes for genetic studies of suicidal behavior. Biol Psychiatry. 2009;65:556-63.

72. Sokolowski M, Wasserman J, Wasserman D. Polygenic associations of neurodevelopmental genes in suicide attempt. Mol Psychiatry. 2015;21:1381.

73. Gross JA, Bureau A, Croteau J, Galfalvy H, Oquendo MA, Haghighi F, et al. A genome-wide copy number variant study of suicidal behavior. PLoS ONE. 2015;10:e128369.

74. Morthorst B, Soegaard B, Nordentoft M, Erlangsen A. Incidence rates of deliberate self-harm in Denmark 1994-2011. Crisis. 2016;37:256-64.

75. Hawton K, Saunders KE, O'Connor RC. Self-harm and suicide in adolescents. Lancet. 2012;379:2373-82.

76. Pruim RJ, Welch RP, Sanna S, Teslovich TM, Chines PS, Gliedt TP. et al. LocusZoom: regional visualization of genomewide association scan results. Bioinformatics. 2010;26: 2336-7.

\section{Affiliations}

\section{Annette Erlangsen ${ }^{1,2,3,4} \cdot$ Vivek Appadurai $^{1,5} \cdot$ Yunpeng Wang ${ }^{1,6,7} \cdot{\text { Gustavo Turecki } \mathbb{D}^{8}}^{8}$. Ole Mors ${ }^{1,9}$. Thomas Werge $\mathrm{e}^{1,5,10}$ - Preben B. Mortensen $\mathbb{1}^{1,11}$ - Anna Starnawska ${ }^{1,12}$ - Anders D. Børglum ${ }^{1,12,13}$. Andrew Schork ${ }^{1,5}$. Ron Nudel $\mathbb{1}^{1,5} \cdot$ Marie Bækvad-Hansen ${ }^{1,14}$ - Jonas Bybjerg-Grauholm $\mathbb{D}^{1,14}$. David M. Hougaard $\mathbb{D}^{1,14} \cdot$ Wesley K. Thompson ${ }^{1,6,7,9,15} \cdot$ Merete Nordentoft ${ }^{1,2,10,16}$ - Esben Agerbo $\mathbb{D}^{1,11}$}

1 The Lundbeck Foundation Initiative for Integrative Psychiatric Research, iPSYCH, Aarhus, Denmark

2 Danish Research Institute for Suicide Prevention, Mental Health Centre Copenhagen, Copenhagen, Denmark

3 Department of Mental Health, Johns Hopkins Bloomberg School of Public Health, Baltimore, MD, USA

4 Center of Mental Health Research, Australian National University, Canberra, Australia

5 Institute of Biological Psychiatry, Mental Health Center St. Hans,
Mental Health Services Copenhagen, Roskilde, Denmark

6 Norwegian Centre for Mental Disorders Research, Institute of Clinical Medicine, University of Oslo, Oslo, Norway

7 Division of Mental Health and Addiction, University of Oslo, Oslo, Norway

8 McGill Group for Suicide Studies, Douglas Hospital Research Centre, Department of Psychiatry, McGill University, Montreal, Canada

9 Psychosis Research Unit, Aarhus University Hospital, 


\section{Risskov, Denmark}

10 Institute of Clinical Medicine, Faculty of Health Science, University of Copenhagen, Copenhagen, Denmark

11 National Centre for Register-based Research (NCRR) and Centre for Integrated Register-based Research (CIRRAU), Aarhus University, Aarhus, Denmark

12 Department of Biomedicine and Centre for Integrative Sequencing, iSEQ, Aarhus University, Aarhus, Denmark
13 Centre for Psychiatric Research, Aarhus University Hospital, Risskov, Denmark

14 Department for Congenital Disorders, Statens Serum Institut, Copenhagen, Denmark

15 Division of Biostatistics, Department of Family Medicine and Public Health, University of California, San Diego, CA, USA

16 Research Unit, Mental Health Centre Copenhagen, University of Copenhagen, Copenhagen, Denmark 